\title{
Involving Community Volunteers in Recording Deterioration of Buildings After Disaster
}

\author{
Chaohsing Huang ${ }^{1}$, Chipang $\mathrm{Lu}^{2} \&$ Yishan $\mathrm{Chen}^{3}$ \\ ${ }^{1}$ Department of Applied Philosophy, Chang Jung Christian University, Taiwan \\ ${ }^{2}$ Research center for Humanity and Social Sciences, National Cheng Kung University, Taiwan \\ ${ }^{3}$ Department of Social Work, Chang Jung Christian University, Taiwan \\ Correspondence: Chaohsing Huang, Department of Applied Philosophy, Chang Jung Christian University, \\ Taiwan.
}

Received: June 19, 2018

Accepted: July 31, 2018

Online Published: August 3, 2018

doi:10.20849/aes.v3i3.435

URL: https://doi.org/10.20849/aes.v3i3.435

\begin{abstract}
On 6 February 2016, an earthquake with a moment magnitude of 6.4 struck southern Taiwan, impacting Meinong District of Kaohsiung. The earthquake caused widespread damage as well as psychological pressure on residents of the area. In Tainan city, there were as many as 5387 requests for building inspections, among them 579 were labeled red (with damage in main structures or tilted that can endanger life) or yellow (with damage of non-main structure). As large number of buildings were damaged, and residents anxious about their safety and possible loss of their properties, technicians from neighboring cities rushed in and sacrificed their time and energy but they barely met the expectations of these affected people.

This report will introduce an experimental project operated in Yujin District, one of the earthquake-affected area, by a team of faculties and graduate students of architecture and community work professions from National Chen Kung University and Chang Jung Christian University. The project, with a series of workshops, aims to facilitate community volunteers with basic skills of portraying and recording deteriorations of a building. As the professional technicians may not be able to reach the damaged area immediately after a serious disaster, the project expects to build up a team that is able to collect basic information of affected buildings so that the professionals can prioritize their inspection tasks.

Due to previous collaboration in community development projects, the team were welcomed by local credit union and they worked with its volunteer group which is one of the major voluntary forces in the region. For the workshops, we simplified the procedures of recoding a deteriorated building, tested and received feedback from the community beforehand so that it will be feasible for lay people to use. Each workshop ended with a new homework for next session so that the learning experience can keep building up. Each workshop was also followed by a team meeting to review the achievements of the workshop and to revise the original design for the next session. Two 'LINE' groups were formed. One was for the project team and the other for all the participants. The LINE group of the team involved leaders from the credit union to make the project transparent to community. The participants' LINE group became handy for homework submission. The LINE app is a good venue for all members to communicate between workshop sessions. An evaluation form was filled by participants at the end of each workshop. In-depth interviews and focus group involving participants as well as university team will be conducted after all workshops came to an end. By the time of conference, this report will present the design and the practice of the serial workshops, the feedback from the participants, and the reflection and lessons learned from the university team.
\end{abstract}

Keywords: disaster, earthquake, community volunteer, interdisciplinary collaboration, building deterioration

\section{Preface}

On the early morning of February 6, 2016, a 6.6 magnitude earthquake hit Meinong District of Kaohsiung. According to Central Weather Bureau, the largest magnitude 7 is in Sinhua District of Tainan. In Pingtung, Kaohsiung, Tainan and Chiayi Area, a quake with 5 magnitudes was observed. The quake shook and damaged buildings. A residential building named Weiguan Jinlong in Yongkang District of Tainan collapsed, causing 115 deaths. The 10-storey building of Hsinhua branch of King's Town Bank buckled and tilted, endangering the 2nd 
and 3rd floor of nearby residential buildings. It was fortunate that no one was trapped. Shop fronts on the 1 st and 2nd floor of the 7-storey building in Gueiren District was collapsed. The 7-storey building was reduced to merely 4 floors. Storeys over the 3rd floor were residences. Luckily, all trapped victims were rescued out.

After the earthquake, Tainan and Kaohsiung City Government conducted building inspection immediately. Based on the information released by the Construction and Planning Agency (CPA) and collected by 9 a.m. March 4, 2016, there were 247 buildings in Tainan labeled red whereas 335 buildings yellow. In Kaohsiung, there are 2 buildings marked red, 1 building yellow. Among the red buildings, $7.7 \%$ are totally-collapsed and 3.2\% half-collapsed while $6.5 \%$ are sunken. Among the yellow buildings, $5.7 \%$ have damaged beam columns at first sight whereas 74.5\% have cracks (National Science and Technology Center for Disaster Reduction, 2016).

As mentioned above, there were 582 buildings in Tainan City marked red and yellow. 5378 cases of building inspections were requested. It was conceivable that affected residents were anxious and worried. However, such considerable requests cannot be responded by architects, structure technicians and civil engineering technicians in a short time. As examination period lengthened, affected residents' worry and insecurity would become stronger, placing pressure on the society and engendering political instability.

National Center for Research on Earthquake Engineering (NCREE) has now developed an "Post-earthquake Building Inspection Manual" which people can download from the Internet to preliminarily ascertain the damage severity of their buildings. However, there is still a digital divide between cities and social hierarchies in such abilities of making good use of information and solving problems on their own. Concerning the 2016 Meinong earthquake in Yujing area, online resource is relatively inaccessible to residents.

This research originates from the thinking that when buildings are damaged after large-scale disasters (e.g. earthquake), professional architectural, civil engineering and structural technicians haven't been able to enter affected areas. If there are some tools that can be picked up easily (e.g. forms) provided for community residents to preliminarily describe the conditions and tools that can collect information from local gathering point (e.g. district offices), it may help professionals to quickly evaluate the degree of damage and condition in a disaster area. Since August of 2016, researchers began going to Yujing with professors and students from architecture department to investigate the damage condition and conduct autonomous building inspection. In November, 2016, researchers talked to some of the community representatives and found that the inspection forms already simplified by professionals are still too complicated to residents. With residents' suggestions, empowering community volunteers on building damage evaluation was adopted instead. It is hoped that through the process a group of volunteers could be cultivated and the original drafted evaluation forms could be adjusted.

\section{Literature Review}

After 921 Earthquake hit Taiwan in 1999, disaster prevention community programs for total community began to appear in large amounts and scales. Such programs have also been flourishing after Typhoon Morakot. The conception of disaster prevention community stemmed from disaster rescuing, gradually expanding from emergency response and disaster preparation to other aspects such as disaster reduction planning. Its operative methods have changed from uni-directional disaster prevention education and promotion to civil participation. If this is really the case, constructing grassroots community ability will be the foremost disaster prevention and rescuing issue. Deng (2004) said when introducing community disaster prevention that it needs residents' participation and learning in normal times in order to understand the community in various aspects such as its characteristics, safety and disaster prevention. By discussing with both sides and with the help of administrative and professional staff, disaster prevention and rescuing strategies and planning can be drawn up. Also, with disaster reduction, precaution and response measures applied, rates of disasters and disaster-causing factors may be decreased. He also conveyed that the process of community disaster prevention is itself an educational process. Residents' participation during the process is significant.

However, Liu and Chen (2015) deemed that ineffective communication between professionals and community organizers results from different expertise of them. Residents' lack of professional knowledge causes the information conveyed insufficient. On the other hand, residents are often mobilized to participate in various activities but do not take part in launching projects, planning activities, exhibiting achievements and so on. They suggest that community disaster prevention require interdisciplinary communication and more community participation instead of uni-directional audience.

For community disaster prevention education, Wu \& Kang (2007) claimed that the execution of disaster prevention community in Taiwan mostly centers on operative methods like trainings, drills and evacuation planning. Although many disaster prevention community project emphasize the importance of civil participation and involves disaster reduction and risk communication issues, most of them still focuses on the pedagogy of 
disaster-related knowledge and unidirectional educational promotion as the main operation (Wu, Kang, 2007; Kuo, Juang, Kang, 2007). The above-mentioned Taiwan community disaster prevention related courses include environment inspection, disaster prevention map drawing, discussion on disaster prevention and rescue strategies, establishment of disaster prevention and rescue database, disaster risk evaluation and so on. Aside from this, the disaster prevention courses of Wang \& Chen (2015) focuses on aboriginal tribes, including examination on slope disaster signs, community environment inspection and map production. These courses are about learning how to prevent slope disasters from happening, explore regions where disasters usually inflict upon and draw maps of disaster prevention resource and landslide potential rivers. The contents of education are undoubtedly related to disaster prevention and response. How to achieve the effect of collaborative learning of community and professionals is what educators interested in community disaster prevention are deeply concerned.

As for the execution of community disaster prevention educational courses, Chuang (2016) conducted a feasibility research, examining disaster risk information in Taiwan by using disaster reduction guidelines of Sendai, Japan. Most disaster risk educational projects in Taiwan revolve around disaster prevention training of teachers and courses planning. For example, Soil and Water Conservation Bureau (SWCB) offers landslide disaster prevention training to teachers and designs landslide propaganda car for residents in mountain areas. Through landslide theatre and game experience, residents would have better understanding of landslide. Water Resource Agency (WRA) provides multiple disaster prevention educational courses on flood report. National Fire Agency (NFA), on the other hand, holds educational training to village chiefs. For courses of disaster risks, Water Conservancy Agency made use of online platform, offering disaster prevention knowledge. Combined with the disaster prevention education of Ministry of Education toward primary schools and junior high schools' teachers and students, SWCB trained volunteers in picture book storytelling, conducting experiment for experience, lesson plan creation and play performance which can be applied in their future courses. WRA took part in issuing curriculum guidelines and teaching materials, incorporating disaster prevention education into Grade 1-9 Curriculum. NFA adopted the community disaster prevention operation manual and community disaster prevention digital learning courses, holding disaster prevention drills and exercises in order to promote community disaster prevention education. Ministry of Education applied digital education, setting up a disaster prevention education platform to provide related teaching materials and offering questionnaires for teachers to evaluate students' learning outcomes. In general, community disaster prevention education tailored to a single community is relatively rare.

From Taipei's experience, Chou \& Wu (2014) concluded that only when the government, professionals and the community work together can a disaster-resistant community be established. They deemed that community leaders in Taiwan have limited understanding of disaster prevention and disaster-resistant community. They provide more general principles in actual community disaster prevention education. Among them, "workshops" and "observation" are the main activities mentioned in this article that can be applied to elevate residents' awareness and capabilities. Kuo, Chuang \& Kan (2011) found in their research of community disaster prevention learning influence factors that community residents considered drills not suitable for all people to participate in and may become a waste of government expenditure. It would be more appropriate for community leaders to receive intensive disaster prevention training. Once they take on the responsibilities of disaster prevention and rescuing, their sense of honor and responsibility will be aroused and thus community disaster prevention education can be pushed forward effectively. Residents' participation is indispensable to effective community disaster prevention education while drills is of great importance to effective learning of residents. The drills have transformed residents from passive knowledge recipients into active participants. Witvorapong, Muttarak \& Pothisiri (2015)'s research in Thailand discovered that those who involve themselves more in community activities are more willing to adopt disaster prevention measures in community education.

The scale and extent of the drills can either be large or small. Some involves a street while others mobilize all city residents; Some conduct simulation on paper while others operate in real situations. In his research on San Francisco communities, Simpson (2002) pointed out that a good drill requires a complete planning. No matter what comes out after the drill, the community can still benefit from it. Since disasters are unexpected, it is common to have chaos. His study also specifies an important effect. If the community actively participates in drills, it will produce a political effect. The Elected Chief will invest more resource in disaster prevention and their influence will in turn be much more useful than scholars and professionals.

The community disaster prevention response serial workshop of "Building Deterioration Volunteer Empowerment" observed in this study has been carried out by three different departments' professors and students from two universities. Wise (2007) reported one Christian university in Kentucky formed new 
partnerships with the community as a result of completing a yearlong practice drill. The drill served to bring local government, non-government organizations, the university and the community closer, enhancing their mutual trust and increase collaborative opportunities.

Based on the above experience and literatures, this program combines community work and architectural profession, collaborating with Meinong earthquake affected Yutian of Yujing area and its surrounding community. The aim is to cultivate a group of building deterioration autonomous inspection volunteers for future building damage inspection at the first moment, fostering their ability of autonomously inspection through more than 4 times' workshops. In a series of workshops and working meetings, they would hopefully develop proper recording tools and pedagogies. This research observed, interviewed and recorded the feelings and thinking of workshop members.

\section{Implementation Process}

\subsection{Community Participation: Multiple Layers of Communication}

In order to expand civil participation, and concerning community disaster prevention in the future requires interdisciplinary communication, mutual learning and multiple layers of community participation, the empowering process involves four kinds of participation: (1) Community First Visit, (2) Preparation Work and Trial before the Workshop (3) Serial Workshop (4) Questionnaire Survey and Focus Group.

\subsubsection{Community First Visit: Establishing the Relationship Between Professionals and Community Residents}

First, the research team established a relationship with the community by interviewing affected residents, village chiefs and the Credit Union. From 2016 May to June, the team has interviewed 12 disaster-affected households in Yutian of Yujing Area. Among the 12 households, 4of them were not labeled damaged. The interview content includes damage severity, repair expenditure on hired labors, time schedule, assistance and subsidies from professionals, non-government and government organizations.

The past positive collaborative experience of professors and students in community work profession in Yuing area enabled the team to establish a relationship with the community successfully. Besides, voluntary team from the community organization (i.e. Yujing Credit Union) is well-established and has experience in receiving educational training. As a result, they are open-minded to the arrangements of the serial workshops.

\subsubsection{Workshop Preparation Work and Trial: Visiting Village Chief and Community Organization Yujing Credit} Union

Before empowerment courses began, we interviewed cadres of the Credit Union and disaster-affected households who had taken part in doing the drafted building deterioration survey. Based on building deterioration situations of the affected households, we drew up the design and conducted the trial of the workshop. Then, we discussed with the village chief, cadres of community organization and affected households to collect their feedback and revise the initial design. According to the conclusion drawn from the process of discussion, the progress of the four workshops were arranged.

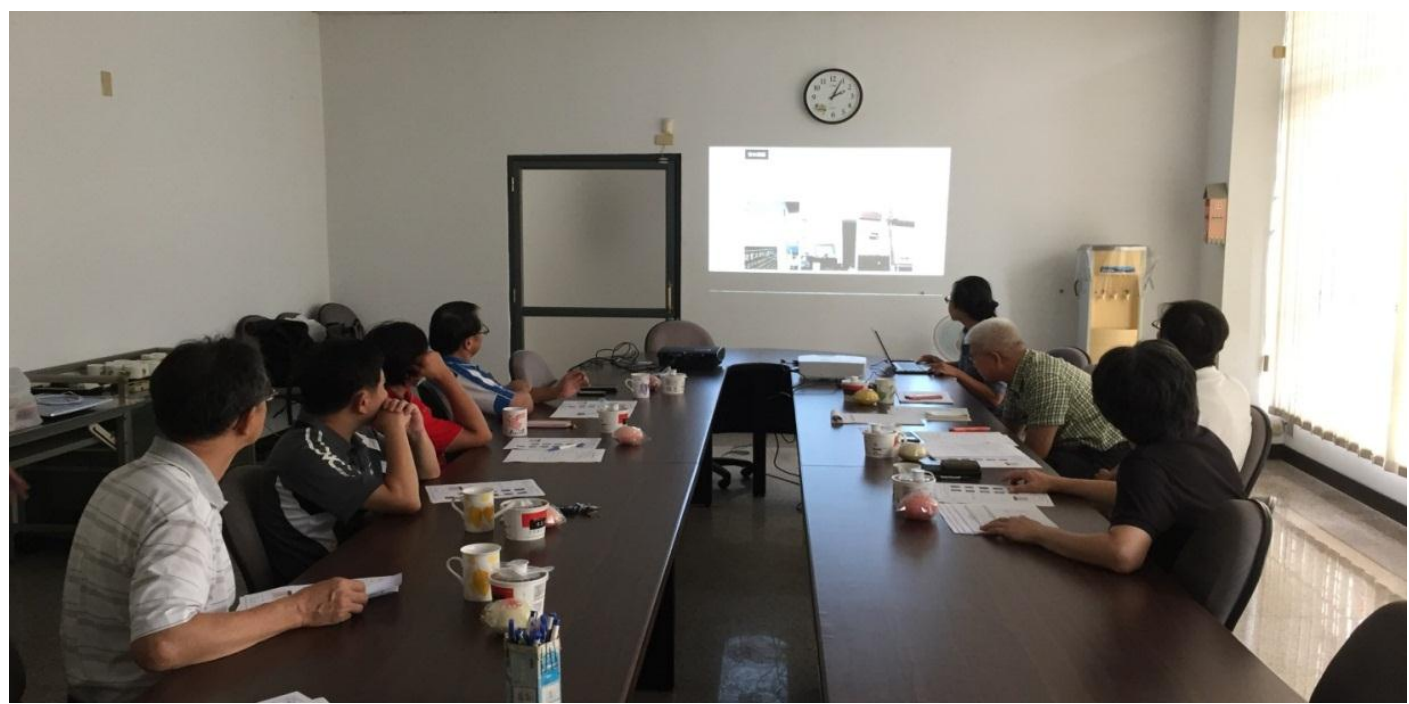

Figure 1. Yujing autonomous building deterioration survey preliminary result report(Oct. 31, 2016) 


\subsubsection{Serial Workshop: Rolling Teaching Design}

The workshops adopted rolling teaching. Every time the lecturer would assign homework for the next session before dismissing the class. Professors and students in architecture profession would adjust their teaching according to the feedback from the community in each class. As a result, residents without the professional background could easily pick up the assignments. Before each class the lecturer would ask prize questions to help community residents review what they learned in the previous class. Each workshop would end with a questionnaire survey and a team meeting to review the previous workshop experience and adjust the procedure for the next workshop.

To facilitate the proceeding, we formed two groups on the social media LINE. One is the working team. The other is for volunteers. Representatives of the voluntary group were also added to the group of the working team to ensure the transparency of discussion. The LINE group for volunteers is very helpful in homework submission, presentation and discussion on course schedule.

\subsubsection{Questionnaire Survey and Focus Group}

Besides the first workshop, questionnaire survey was conducted in the following three workshops. Participants were asked two kinds of questions: "Learning Harvest" and "Activity Satisfaction." For questionnaire format, the first section asks participants their harvest level at each stage based on the activity procedure of that time (Table 2), which also serves as a reminder of the activity process and content. The second section is the administrative satisfaction (Table 3). Results of every questionnaire survey are as follows.

Table 1 shows that the participants of the workshop hosted in Yujing Credit Union were kept above 23 people. This could be accounted for the strong mobilizing ability of Yujing Credit Union Voluntary Team and the workshop design that is of interest to volunteers' continuous participation. The empowerment team kept emphasizing that this is the first voluntary team of this kind in the country and therefore spur their sense of honor. As people had to go to Zuojhen District from Yujing and the day of workshop bumped into busy farming seasons, participants of the forth workshop were fewer.

Regarding the harvest level of the workshop, as shown in Table 2. The design of each Ice Breaker Activity has obtained score above 4.36 in Stage Design and Hands-on Exercise. As for the harvest of professional courses, including building deterioration investigation, drills and course-end presentation and so on, all got score around 4.5 as feedback.

Considering workshop satisfaction, the workshop was hosted in an auditorium that could accommodate over 200 people. For about 30 actual participants, the space was too large. The course only used $1 / 3$ of the space in layout design. But the sufficient space had enabled volunteers and assistants to move freely between the segmented space. The activity lasted from 6:30pm $\sim 9$ am in week days, which was quite a challenge to adults. Items including venue, time arrangement, desserts and staff services in administrative satisfaction of workshop all received high scores (Table 3 ). The administrative efforts might have some contribution to the continuous participation of members.

Table 1. Attendance of workshop participants

\begin{tabular}{cccc}
\hline Session & Date/Time & Place & Number of People \\
\hline Workshop I & $2016.12 .20,19-21 \mathrm{pm}$ & Yujing Credit Union & 24 \\
Workshop II & $2017.1 .3,9 \mathrm{am}-21 \mathrm{pm}$ & Yujing Credit Union & 25 \\
Workshop III & $2017.1 .10,19-21 \mathrm{pm}$ & $\begin{array}{c}\text { Yujing Credit Union } \\
\text { Caoshan Village Activity Center } \\
\text { (previously Ganglin Elementary } \\
\text { School Caoshan Branch) }\end{array}$ & 23 \\
Workshop IV & 2017.3.4, 9am-15pm & 15 \\
Hands-on Drills & & . & \\
\hline
\end{tabular}


Table 2. Workshop learning effect (Harvest Level)

\begin{tabular}{|c|c|c|c|c|c|c|c|c|c|c|c|c|}
\hline \multirow[t]{2}{*}{ Variable } & \multicolumn{2}{|c|}{ Very Low } & \multicolumn{2}{|c|}{ Low } & \multicolumn{2}{|c|}{ Medium } & \multicolumn{2}{|c|}{ High } & \multicolumn{2}{|c|}{ Very High } & \multirow{2}{*}{$\begin{array}{l}\text { Me } \\
\text { an }\end{array}$} & \multirow{2}{*}{$\begin{array}{c}\text { Percen } \\
\text { tage }\end{array}$} \\
\hline & Time & $(\%)$ & Time & $(\%)$ & Time & $(\%)$ & Time & $(\%)$ & Time & $(\%)$ & & \\
\hline $\begin{array}{l}\text { Course Historical Review } \\
\text { (Icebreaking) }\end{array}$ & 0 & (.0) & 0 & (.0) & 0 & (.0) & 9 & $(64.3)$ & 5 & $(35.7)$ & 4.36 & 87.14 \\
\hline $\begin{array}{l}\text { Investigation Homework } \\
\text { Explanation and Grouping }\end{array}$ & 0 & $(.0)$ & 0 & (.0) & 0 & (.0) & 7 & $(50.0)$ & 7 & $(50.0)$ & 4.50 & 90.00 \\
\hline $\begin{array}{l}\text { Building Deterioration } \\
\text { Investigation Hands-on } \\
\text { Drills }\end{array}$ & 0 & (.0) & 0 & (.0) & 0 & (.0) & 6 & $(42.9)$ & 8 & $(57.1)$ & 4.57 & 91.43 \\
\hline $\begin{array}{l}\text { Course-end Presentation } \\
\text { Building Deterioration }\end{array}$ & 0 & (.0) & 0 & (.0) & 0 & $(.0)$ & 8 & $(57.1)$ & 6 & $(42.9)$ & 4.43 & 88.57 \\
\hline $\begin{array}{l}\text { Investigation On-the-spot } \\
\text { Discussion of Notices }\end{array}$ & 0 & (.0) & 0 & (.0) & 0 & $(.0)$ & 7 & $(50.0)$ & 7 & $(50.0)$ & 4.50 & 90.00 \\
\hline Ceremony of Completion & 0 & $(.0)$ & 0 & $(.0)$ & 0 & $(.0)$ & 6 & $(42.9)$ & 6 & $(42.9)$ & 4.50 & 90.00 \\
\hline
\end{tabular}

Table 3. Workshop effect (Satisfaction)

\begin{tabular}{|c|c|c|c|c|c|c|c|c|c|c|c|c|}
\hline \multirow{2}{*}{ Variable } & \multicolumn{2}{|c|}{ Very Low } & \multicolumn{2}{|c|}{ Low } & \multicolumn{2}{|c|}{ Medium } & \multicolumn{2}{|c|}{ High } & \multicolumn{2}{|c|}{ Very High } & \multirow{2}{*}{ Mean } & \multirow{2}{*}{ Percentage } \\
\hline & Time & $(\%)$ & Time & $(\%)$ & Time & $(\%)$ & Time & $(\%)$ & Time & $(\%)$ & & \\
\hline $\begin{array}{c}\text { Time } \\
\text { Arrangement }\end{array}$ & 1 & (4.17) & 0 & 0 & 1 & (4.17) & 10 & (41.67) & 12 & 50 & 4.33 & 86.67 \\
\hline $\begin{array}{c}\text { Place } \\
\text { Arrangement }\end{array}$ & 1 & (4.17) & 0 & 0 & 1 & $(4.17)$ & 8 & (33.33) & 14 & 58.33 & 4.42 & 88.33 \\
\hline $\begin{array}{l}\text { Staff Service } \\
\text { Attitude }\end{array}$ & 1 & (4.17) & 0 & 0 & 1 & (4.17) & 8 & (33.33) & 14 & 58.33 & 4.42 & 88.33 \\
\hline
\end{tabular}

In addition, after finishing all the learning workshops a focus group was gathered to collection comments and suggestions of teachers, students and community volunteers. See Table 4 for focus group questions for discussion. And see Table 5 for focus group participants. Feedback from other related personnel are as below:

1) Volunteers had the experience of receiving educational training and were open-minded to the arrangement of the workshop.

About the operation of the workshop, both the Q\&A section in the beginning of the class or the after-class assignments all could give volunteers a sense of honor and responsibility.

2) Assistants with professional ability were of help to interdisciplinary communication and mutual learning.

As building deterioration autonomous inspection is a kind of new knowledge to volunteers, besides learning in the courses, it requires some practical skills such as building deterioration recognition, drawing and filling in forms. For those volunteers who lack related professional ability, "It's a new knowledge and needs practical operation. We would be confused if the instructions are not clear enough..." (A2) But with the help of assistants in the workshop, "Practical operation? Sometimes we couldn't understand at once, but if the assistant explained again, learning would become much easier. And there was a sense of warmth!" (A2)

3) Volunteers had difficulties in using Internet social community tools.

Basically, most Yujing volunteers have the habit of using smart phones, but they do not pay attention to their phone anytime and anywhere or familiarize themselves with smart phone features. As a result, some volunteers said that using smart phones for homework submission was difficult for them.

4) Workshop courses were helpful for the cohesion of the voluntary team, but volunteers also hope for more opportunities for professional learning.

There just a few training courses for the voluntary team. Thus, the workshop had enabled the volunteers to know each other and shorten their distances, which was helpful for the cohesion of the voluntary team. The volunteers also reflected that the percentage of academic materials should be enhanced and some content they did not really get into it. In addition, they were looking forward to more planning and arrangement for the practical exercise.

5) Some volunteers reflected that becoming seed volunteers requires richer courses and ability accreditation. 
When the focus group was about to finish, some volunteers raised their doubts about learning in the workshop: "The more we study, the more we discover our ignorance. We become fearful of not learning enough."(A3) "Without rich knowledge background, how could we serve others?"(A4) "The following questions are that are we able to undertake a mission? Do we need any equipment?"(A1) Also, some mentioned the responsibility issue of becoming seed volunteers: "There shall be a regulation on the limit of authority for volunteers. The volunteers' credit will not be ruined."

Table 4. Focus group questions for discussion

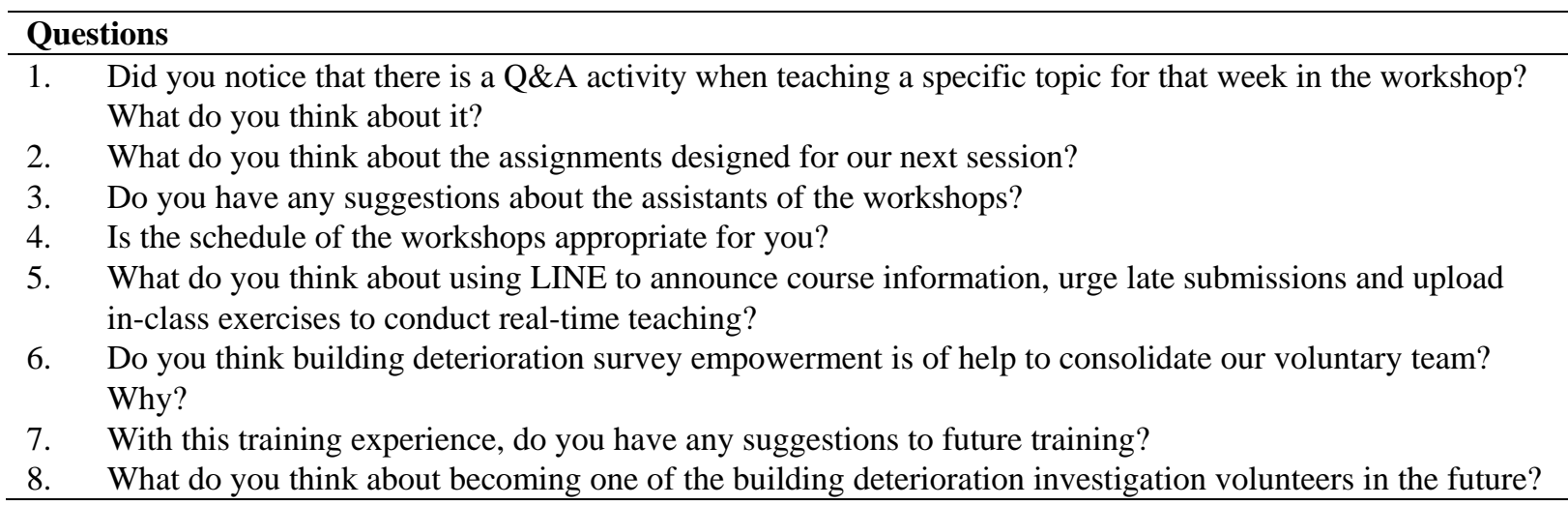

Table 5. Focus group participants

\begin{tabular}{|c|c|c|c|c|}
\hline Code & Institutions & Interviewee & Gender & Age \\
\hline$\overline{A 1}$ & Yujing Credit Union & President & Male & 61 \\
\hline $\mathbf{A 2}$ & Yujing Credit Union & $\begin{array}{l}\text { Vice Managing } \\
\text { Director }\end{array}$ & Male & 67 \\
\hline $\mathbf{A 3}$ & Yujing Credit Union & Manager & Female & 61 \\
\hline A4 & Yujing Credit Union & Volunteer Chief & Female & 54 \\
\hline A5 & Yujing Credit Union & Staff & Female & 37 \\
\hline A6 & Yujing Credit Union & Volunteer & Female & 37 \\
\hline C1 & $\begin{array}{l}\text { Research Center for Humanity and } \\
\text { Social Science (CHASS), NCKU }\end{array}$ & $\begin{array}{l}\text { Post-doctoral } \\
\text { Researcher }\end{array}$ & Male & 39 \\
\hline $\mathrm{C} 2$ & $\begin{array}{l}\text { Research Center for Humanity and } \\
\text { Social Science (CHASS), NCKU }\end{array}$ & Adjunct Assistant & Male & 34 \\
\hline $\mathbf{C 3}$ & $\begin{array}{l}\text { Research Center for Humanity and } \\
\text { Social Science (CHASS), NCKU }\end{array}$ & Project Assistant & Male & 28 \\
\hline
\end{tabular}

\subsection{Interdisciplinary Interactive Learning in the Workshop}

Since professionals and community organizers have different specialties, the teaching method of disaster prevention professional knowledge requires effective communication with the community. On the other hand, community residents should be equipped with the ability and tools to send and respond to the local information. The plan and design of the serial workshop in this study features the following:

\subsubsection{Workshop Preparation Communication and Trial}

The serial workshop was arranged based on the preparation work of the interview from May to June and training courses on draft design and trial from August to September in 2017. Then professionals would discuss with the community and plan a series of workshop in accordance to the actual problems community residents in Yujing area faced on February 6, 2016 in the direction of autonomous self-inspection of building deterioration after the earthquake.

3.2.2 Course Assistants With Professional Background Facilitated Community Residents in Understanding Professional Knowledge and They Also Collected Residents' Feedback

In the serial workshop, each time there were 25 community volunteers divided into 6 groups with 3 assistants in architectural background assisted in discussion and practices such as house space allocation drawing, 
discrimination and indication of deterioration phenomena and deterioration recording. For volunteers lacking professional knowledge and training, course assistants with professional backgrounds provided them with real-time feedback and communication regarding professional knowledge transfer and graph drawing and filling in forms. In the course, the questions raised by community volunteers offered real-time feedback and communication in professional knowledge. In contrast, course assistants could receive direct feedback from community residents concerning their learning in professional knowledge and have the chance to revise their course design for the next course.

On the other hand, between every workshop community volunteers were arranged homework assignments centering on residents' building related data collection. As the assignments required the use of social media and not all the community residents were able to use the function, partly because some didn't own smart phones and some didn't have network connection in their phones, the course assistants would help the volunteers and check if they knew how to use the function. During the process, the assistants would also check if the contents uploaded by the volunteers were as the same with what he or she wanted to express.
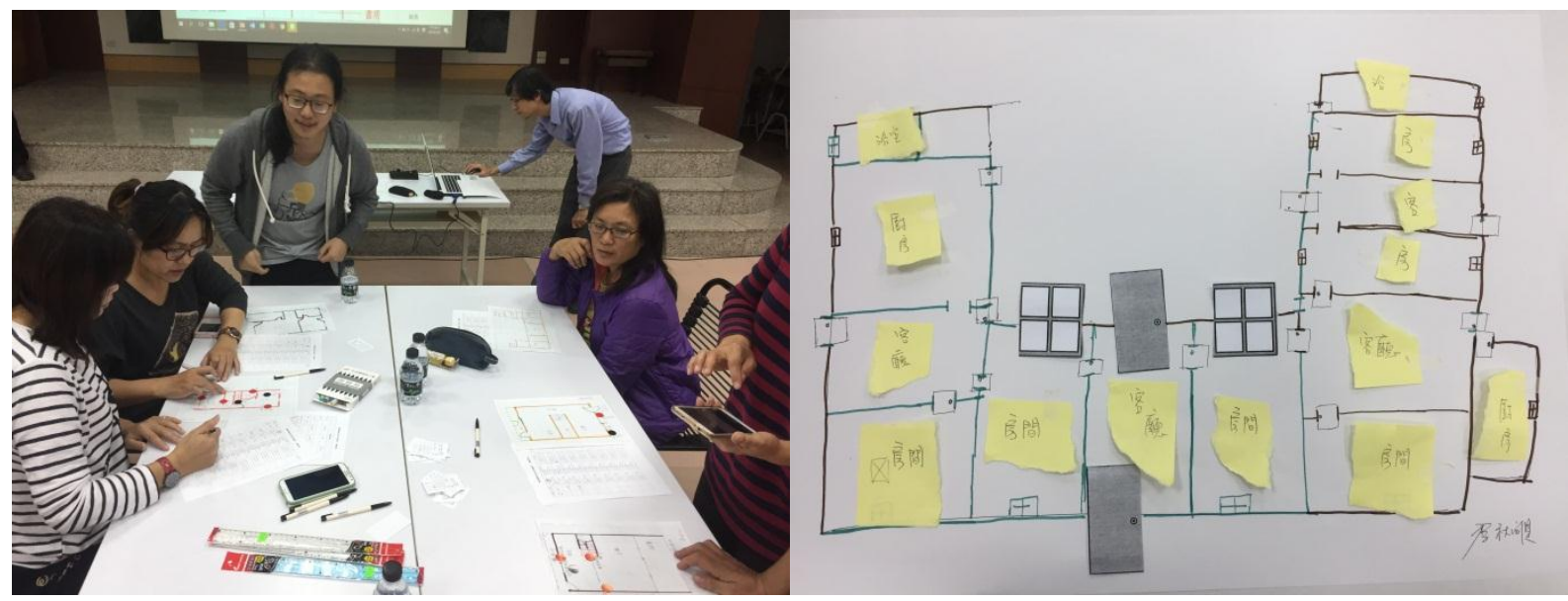

Figure 2. Yujing Credit Union disaster prevention workshop (Dec. 20, 2016)

(Course assistants helped volunteers drawing and labelling space allocation graphs of their houses.)

\subsubsection{Reflexive Learning Through Building Deterioration Drills}

The last workshop was hosted in the campus of one abandoned elementary school, where buildings were severely damaged after the earthquake on February 6. In this drill course, volunteers served as the main practitioners. In addition, students from non-architecture backgrounds of Chang Jung Christian University acted as learners. The volunteers would teach students how to inspect building at the site. After the course, there was a presentation of inspection outcomes and reflection sharing on the drills.

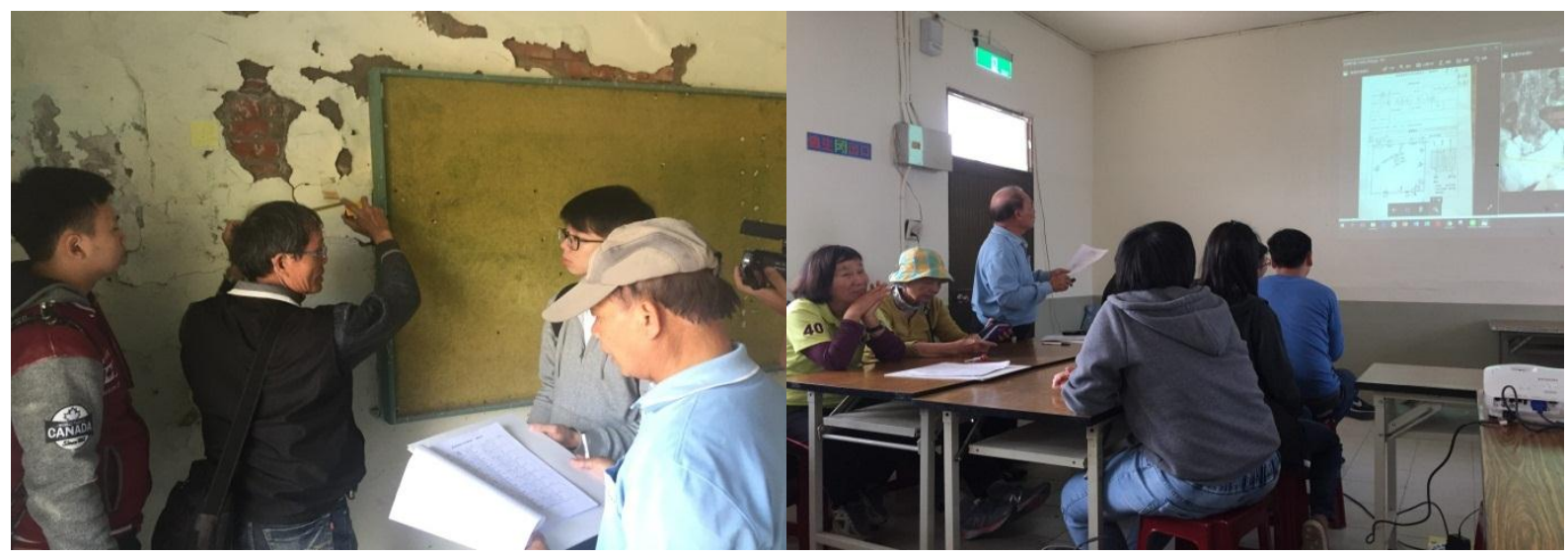

Figure 3. Yujing Credit Union Disaster Prevention Workshop Final Drills (Mar 4, 2017) 
3.2.4 Professionals and Community Residents Maintained Their Conversation Through Social Media (LINE) Once a Disaster Occurs in the Future

Between every workshop, social media served as a tool to help residents collecting data of their buildings for homework assignments. The social media group is still functioning after the workshop ended. After the earthquake on February 6, 2016, the groups sent messages to each other and offered helps for the earthquakes on February 11, 2017 and February 6, 2018. Community volunteers showed their regard and caring while the professionals played the roles of reminding them related professional problems. The key lies in that since these volunteers had the professional knowledge, they were able to understand and respond to professionals' inquiry and response and conducting related autonomous inspection and responses.

\section{Lessons and Reflections}

Collecting opinions from focus group participants, this study divides the section of lessons and reflections into the following two parts. One is the process and the other is the impacts and implementation section.

\subsection{The Empowerment Process}

1) In the empowerment workshop, the content of the training appeared repeatedly through the ways of pre-assignments, Q\&A review and use of social media, which can boost participants learning effects. Volunteers considered it "a sense of honor and that feeling is quite good."(A1) "You had to prepare at home as you have the responsibility." (A4) "Because of the assignments, we have the motivation to turn in homework and share with others what I have done."(A3)

2) The assistants had double functions in the workshop. On the one hand, they helped participants finish their assignments at once. On the other, they could report the operative situations and difficulties of participants to the instructor of the workshop. "On-site operation? Sometimes we couldn't understand at once, but if the assistant explained again, learning would become much easier. And there was a sense of warmth!" (A2) Also, the most difficult part of the course is drawing. "Actually, for me drawing is quite a trouble. I don't know how to draw. But I am thankful for their instruction...I really appreciate them!"(A6)

3) Some people were still unable to use smart phones and Internet social community application. And therefore, it could not be the only and one way of communication. "The course itself isn't hard, but how to send the message is difficult for me." (A3) "Some didn't get used to sending questions via phones..." (A1) "When someone sent a message to me and hoped for my reply, I would hand-write on the screen but the result wasn't right...Sometimes I thought calling the person would be easier.”(A2)

\subsection{Impact and Following Development}

1) The launch of the mission requires volunteers' group action in 2-3 people so as to take both building deterioration record and the trust and interaction of disaster-affected buildings' residents into consideration.

2) The empowerment workshop has provided participants with fundamental knowledge of observing building deterioration, expecting that this would help volunteers to decrease the panic of community caused by lack of information in future similar situations. For example, some volunteers said that "This course has equipped me with preliminary understanding of cracks in a building." Trained volunteers willing to serve others have to be arranged into local disaster response system to fulfill their functions. With knowledge of discriminating building deterioration isn't enough, the volunteers should have empathy and ethics of voluntary service, so that they will be able to take care of the situation of the affected residents. For instance, some volunteers talked about the issue of responsibility: "The following questions are that are we able to undertake a mission? Do we need any equipment?"(A5) Also, "How to enter into others' house, matters for attention and equipment we need to bring, as well as how to sort out the information after inspection should be planned beforehand." (A4)

3) Volunteers should be frequently retrained to maintain mastery of related competence. The Managing Director of Yujing Credit Union also said that "As a managing director, I support our team leader. If our volunteers are still interested and the professor is willing to educate them in the future, it is much welcomed. The future course may go deeper and include more details."(A1)

This article is a record of the learning process of volunteers from Yujing Credit Union of Tainan. Due to the collaborative positive experience of team members and community leaders in the past and various designs of this project, the learning obstacles of volunteers are removed and their sense of achievement toward learning is enhanced. How to continuously maintain a phased positive experience and include trained volunteers into the local disaster prevention and rescue system is an important issue for the next stage that requires the communication and negotiation of local government and professional technician association. 


\section{References}

Chou, J.S., \& Wu, J.H. (2014). Success factors of enhanced disaster resilience in urban community. Natural Hazards, 74(2), 661-686 https://doi.org/10.1007/s11069-014-1206-4

Chuang, M.J. (2016). The Review of Availability of Disaster Risk Information to People in Taiwan, Base on Sendai Framework for Disaster Risk Reduction. Article for the 2016 Conference in Commemoration of Disaster Management Society of Taiwan.

Deng, T.C. (2004, February). An Investigation on Community Disaster Education in Taiwan (I). Fire Safety Monthly, 14-21.

Earthquake Disaster Collection and on-site Survey Report. (2016, March). National Science and Technology Center for Disaster Reduction (NCDR), National Center for Research on Earthquake Engineering (NCREE).

Kuo, C.C., Juang, H.H., \& Kang, L.Y. (2007). A Preliminary Study of Community Disaster Prevention Education: Disaster Areas of Debris Flow. Environment and Worlds, (15), 99-128.

Kuo, C.C., Juang, H.H., \& Kang, L.Y. (2011). A Study on Factors Affecting Community Disaster Prevention Learning. Journal of National Taichung University: Humanities \& Arts, 25(1), 99-123.

Liu, Y.C., \& Chen, L.C.C. (2015). Community-Based Disaster Risk Management: Retrospect and Issues, 4(2), 59-81.

Simpson, D.M. (2002). Earthquake Drills and Simulations in Community based Training and Preparedness Programmes Disasters, 26(1), 55-69.

Wang, J.H., \& Chen, M.F.C. (2015). Risk Adaptation to Climate Disasters of Indigenous Tribe: An Action Research Approach. Journal of the Agricultural Association of Taiwan, 16(3), 197-211.

Wise, G.I. (2007). Preparing for Disaster: A Way of Developing Community Relationships. Disaster Management \& Response, 5(1), 14-17. https://doi.org/10.1016/j.dmr.2006.10.004

Witvorapong, N., Muttarak, R., \& Pothisiri, W. (2015). Social Participation and Disaster Risk Reduction Behaviors in Tsunami Prone Areas. PLoS ONE, 10(7), 0130862. https://doi.org/10.1371/journal.pone.0130862

Wu, J.Y., \& Kang, L.Y. (2007). A Study on Community Disaster Prevention-Take Community Disaster and Rescuing Total Construction Project for Example. Community Development Journal, (116), 213-231.

\section{Copyrights}

Copyright for this article is retained by the author(s), with first publication rights granted to the journal.

This is an open-access article distributed under the terms and conditions of the Creative Commons Attribution license (http://creativecommons.org/licenses/by/4.0/). 